\title{
ALGUNAS REFLEXIONES SOBRE LA POLÍTICA AGRARIA COMUNITARIA
}

\author{
Eugenio CEJUDO GARCÍA \\ Departamento de Geografía Humana. Universidad de Granada. \\ Juan Carlos MAROTO MARTOS \\ Departamento de Geografía Humana. Universidad de Granada.
}

\section{INTRODUCCIÓN.}

Desde la creación de la Comunidad Económica Europea el sector agrario ha desempeñado un papel esencial. Es un sector en el que sus activos cada día son menores (el 5\% de los totales en 1998) así como su aportación al PIB (menos del $3 \%$ del total) y en el que existen 8.000 .000 de explotaciones con una dimensión media de 16,4 has. Pero sería injusto valorar la importancia del mundo rural europeo sólo por la significación de las grandes cifras macroeconómicas de su actividad principal. Si lo hacemos así olvidamos que desde el punto de vista económico el denominado complejo agroalimentario constituye hoy en día una de las actividades productivas que más pesan en la economía comunitaria (supone el $20 \%$ de la producción industrial de nuestro país) y, sobre todo, no tenemos en cuenta que éste forma parte constitutiva de la sociedad y la cultura de Europa.

Para organizar este sector económico se puso en funcionamiento una de las políticas comunitarias que más esperanzas, logros y desilusiones ha generado; nos referimos, evidentemente, a la Política Agraria Comunitaria (desde ahora PAC) en la medida en que ha sido, prácticamente hasta la actualidad, la única política realmente comunitaria de la hoy Unión Europea como lo demuestra el hecho de haber llegado a recibir cerca del $80 \%$ del presupuesto comunitario y seguir absorbiendo hoy en día el 50\% del mismo.

Nuestro propósito en las siguientes páginas es el de reflexionar sobre las bondades y las incoherencias de la PAC en su etapa más reciente, la que se inicia en 1992. Del mismo modo, pretendemos aportar algunas consideraciones sobre los retos a los que se enfrenta en los próximos años en un contexto marcado por la ampliación hacia el Este de la Unión Europea y por el proceso de globalización en la que cada vez se ve más inmersa.

\section{UN LARGO CAMINO HASTA 1992. LA CRISIS DE LA PAC COMO CONSTANTE Y CONSECUENCIA NECESARIA DE SU ÉXITO.}

El largo camino que conduce a la PAC desde su origen hasta la reforma de 1992 viene marcado por su cuestionamiento y la necesidad casi constante de reforma. Como señala F. MOLINERO (1990) ésta ha surgido de un conflicto de inte-

Polígonos, $\mathrm{n}^{\mathrm{o}}$ 10, 2000, pp. 61-83. 
reses entre la CEE y los países terceros, por una parte, entre productores y consumidores, por otra, y entre países miembros, finalmente. El conflicto de intereses entre la CEE y países terceros arranca de la propia filosofía proteccionista de la PAC. Surge también como un conflicto de intereses entre productores y consumidores en la medida en que precios altos para los productos agrarios beneficiaban a los productores en contra de los consumidores y viceversa. Conflicto de intereses entre países miembros ya que ésta no puede ser considerada como una política aislada y separada del resto de la política económica, pues frecuentemente las concesiones o los privilegios agrarios entre países se utilizaban como moneda de cambio para conseguir otros objetivos.

A pesar de que la reforma ha sido un proceso continuo es posible, a nuestro entender, diferenciar, sin ánimo de exhaustividad, varias etapas en su devenir histórico.

Una gran primera etapa, que podría ser denominada como de "normalidad", abarcaría hasta el inicio de la década de los ochenta y se caracterizaría por una política básicamente de precios, en la que las actuaciones de carácter estructural tienen un lugar absolutamente marginal siendo sólo destacable la aparición en 1975 de las Directivas 268 y 269 sobre Zonas de Montaña y Desfavorecidas, y donde apenas existe control de las producciones agrarias. A pesar del calificativo de "normal" en esos años se empiezan a manifestar de forma clara algunos de los grandes problemas de la PAC por lo que en 1968 se produce un intento de reforma por parte del Comisario de Agricultura Sicco Mansholt a través del Plan que lleva su nombre. Se propugnaba en él, básicamente, la reducción de los activos agrarios, de la superficie cultivada e incremento de la forestal y de la contención de la producción de leche.

La segunda, que abarcaría toda la década de los ochenta hasta 1992, viene marcada, en primer lugar, por el intento de reformarla a través de medidas que pretendían congelar el gasto (para lo que era necesario limitar el crecimiento de la producción que además se podría disparar con la incorporación de dos grandes potencias agrícolas como eran España y Portugal). Ello se tradujo en 1984 en el establecimiento de las tasas de corresponsabilidad para el caso de los cereales y de las cuotas de producción para la leche. En 1987 se impone la disciplina presupuestaria en materia agraria a través de nuevos estabilizadores (fijándose Cantidades Máximas Garantizadas para las producciones agrarias) y de un límite en el índice de crecimiento del gasto del FEOGA-G a un porcentaje del incremento del PNB de la Comunidad (74\%), con lo que se aseguraba que el aumento del gasto agrícola evolucionaría en el futuro por debajo del incremento general de la economía.

En segundo lugar, por la puesta en marcha en 1987 de la dimensión "negativa" o restrictiva de la política de estructuras para adaptarla a un contexto estabilizador a través de ayudas destinadas a fomentar la reconversión y extensificación de la producción a las que se les incorpora un fuerte carácter medio ambiental. Un año después, en 1988, se ponen en funcionamiento las ayudas destinadas a la retirada de tierras (set-aside), al abandono anticipado de la actividad agraria (prejubilación) y al fomento de las zonas forestales.

Finalmente, el cambio más significativo es el que se produce en el discurso comunitario al enfatizarse en la necesidad de considerar los problemas de los agri- 
cultores en el entorno rural, y no sólo como productores agrarios. El desarrollo agrario va a ser sustituido por el desarrollo rural y la mejora de la renta agraria por la pluriactividad.

La tercera (en la que nos encontramos inmersos y es la que aquí nos interesa), arranca con la reforma de 1992.

\subsection{Los detonantes de la reforma de $\mathbf{1 9 9 2 .}$}

El insostenible problema de los excedentes y del gasto agrario.

El colchón de seguridad que les ofrece a los agricultores y ganaderos de la Comunidad un precio y comprador garantizados hace que las producciones agrarias se incrementen espectacularmente con el paso de los años, especialmente en aquellos productos (denominados continentales) en los que los países fundadores de la CEE estaban especializados. El CUADRO $\mathrm{N}^{\mathrm{o}} 1$ refleja la situación existente a finales de 1985, momento en el que aún no se habían incorporado a la Comunidad los Países Ibéricos, y 1996. Al contrario de lo que pudiera parecer, es el sector ganadero y no el agrícola el que genera mayores excedentes si se tiene en cuenta el valor de los mismos ya que, de los cerca de 10.600 millones de Ecus que suponen su monto total, casi 6.600 (el 62\%) son derivados de productos ganaderos y los 4.000 restantes son agrícolas (el otro 38\%), destacando sobremanera la mantequilla (32\% del total) y la carne de vacuno tanto en canal como deshuesada (con otro $21 \%$ ). Las producciones continentales son las únicas responsables de los excedentes de la Comunidad puesto que los productos mediterráneos no tienen significación en ese año ni en 1996.

Como no podía ser de otra manera, conforme crecía la maquinaria productiva agrícola comunitaria, a través del incremento constante de los rendimientos que la dinámica del mercado impone, se iba incrementando el volumen de presupuesto que dentro de la CEE se destinaba a la PAC (CUADRO N $\left.{ }^{\circ} 2\right)$. Con este volumen de dinero concedido al FEOGA no es de extrañar que la partida dedicada al gasto agrario dentro de la UE fuera y siga siendo, con diferencia, la más importante. En efecto, en 1970 suponía casi el $90 \%$ del presupuesto comunitario, porcentaje que se reduce al $70 \%$ en 1980 y al 52\% en 1999 . Otra conclusión que puede extraerse de las cifras es que la inmensa mayor parte del presupuesto del FEOGA se canalizaba a través de su Sección Garantía, o lo que es lo mismo, la mayor parte del presupuesto en materia agraria se destinaba a la política de precios, quedando la de estructuras totalmente relegada como lo demuestra el hecho de que ésta, entre 1970 y 1988, jamás haya superado el 3\% del presupuesto comunitario; bien es cierto que, a partir de esos momentos, sufre un considerable incremento hasta situarse en el 8,6\% de 1999 .

De estas cifras se podría llegar a la conclusión de que en Europa los gastos en materia agraria resultaban y resultan aún excesivos. Nada más alejado de la realidad, téngase en cuenta que en la Comunidad, a diferencia de cualquiera de los Estados que la forman, no se destinan presupuestos a los demás gastos generales de cualquier país (sanidad, educación, defensa, policía, etc.), que siguen siendo financiados por los respectivos gobiernos nacionales. Al faltar aquéllos, es normal que el gasto se concentre en la PAC al haber sido casi la única política realmente comunitaria de la CEE. Si por el contrario relacionamos estos gastos con el PIB 
comunitario, los destinados al sector agrario suponían en 1998 el 0,6\%, valor similar al que se da en países como USA.

Los desequilibrios sociales y espaciales. Productos continentales frente a mediterráneos.

Pero lo que hacía aún más insostenible esta situación es que el espectacular despliegue presupuestario no había servido para elevar significativamente la renta de los agricultores y menos aún para igualarla a la de los trabajadores de otros sectores económicos; es más, había incrementado la desigualdad entre trabajadores y explotaciones dentro del propio sector. En efecto, el documento presentado en febrero de 1991 por la Comisión denominado Evolución y futuro de la PAC. Documento de reflexión (1991a) señala la contradicción existente entre la elevación constante del gasto agrario y la escasa mejora de las rentas de sus trabajadores. Es más, se reconoce que el $80 \%$ del dinero público repartido por la PAC había ido a parar a las arcas del $20 \%$ de las explotaciones más productivas e intensivas en capital. Este hecho se explica como consecuencia de una política de precios que premia a aquellas explotaciones que obtienen mayores volúmenes de producción y, especialmente, a las que los consiguen con menores costes, así como a las que se especializan en las producciones más protegidas. Dicho de otro modo, en Europa ni existe una agricultura europea, ni existe una ganadería europea y menos aún un sector agrario europeo.

Si este hecho es evidente, no lo es menos el desigual apoyo que la PAC ofrece a las diferentes producciones agrarias, tal y como se puede comprobar en el CUADRO N $^{0} 3$ en el que se ofrecen datos referidos a 1985 y 1996 . El resultado no ofrece ninguna duda; existe una clara sobreprotección de los productos continentales frente a los mediterráneos tanto en 1985 como en 1996 y, lo que es todavía más llamativo, ésta se ha incrementado con el paso del tiempo a pesar de la integración de los países ibéricos; bien es verdad que en 1996 ya se había producido la integración de Austria, Finlandia y Suecia con un pequeño sector agrario pero típicamente continental. Si observamos el CUADRO $\mathrm{N}^{\circ} 4$ (el ESP mide el apoyo a los precios más los pagos directos) rápidamente se comprueba que los productos continentales cuentan con un elevado nivel de protección que supera en el caso de los cereales, oleaginosas, azúcar y ovino el $60 \%$ del Valor Añadido Bruto a precios de mercado (VAB a p.m) y en el caso de los derivados del vacuno (carne y leche) se sobrepasa dicha magnitud. Por su parte, en los productos mediterráneos sólo el tabaco y el arroz aparecen como muy protegidos al superar el 100\% del VAB a p.m; por el contrario, en el resto de los productos varía entre el 10,7\% de las frutas y el $33,2 \%$ del aceite de oliva.

Otro aspecto que no conviene olvidar es que no todo el apoyo que reciben los productos mediterráneos va a parar a las arcas de los países del Sur ya que existen otros, como Francia, que también lo percibe; y lo que es más importante, los países del Sur participan también de forma importante en las transferencias realizadas a producciones continentales (ver CUADRO $\mathrm{N}^{\mathrm{o}} 5$ ). En el conjunto de los países del Sur las transferencias del FEOGA-G procedentes de los productos mediterráneos suponen sólo el $41 \%$ mientras que casi el otro $60 \%$ son de origen continental, porcentaje que para el caso de nuestro país es sólo del $23 \%$. No parece por tanto justo responsabilizar del desequilibrio financiero desfavorable de los productos mediterráneos con respecto a los continentales a una menor influencia 
política de los países del Sur dentro de la UE. Éstos son también generadores de muchos productos continentales lo que explica, al menos desde un prisma político, que no se haya hecho mayor presión por parte de este grupo de países para reequilibrar el presupuesto hacia las producciones mediterráneas.

Si los países que conforman la UE tienen una especialización productiva diferente y las ayudas del FEOGA se reparten primando a unos sectores frente a otros, es lógico suponer que habrá países que reciban por parte de dicho organismo para su sector agrario más ayudas que otros, e incluso que éstas sean superiores a las que les corresponderían en función de sus respectivas aportaciones a la PFA comunitaria. Los resultados obtenidos (ver CUADRO ${ }^{\circ} 6$ ) reflejan que tres Estados miembros (Francia, Alemania e Italia) acaparan el 55\% del apoyo total, siendo el primero, con diferencia, el país más beneficiado en términos absolutos por las transferencias de la PAC con el 23,8\% de las mismas. Del mismo modo, son los países del Norte los que registran mayores transferencias por Unidad de Trabajo Año (UTA) (caso de Bélgica Dinamarca y Reino Unido al superar los 20.000 Ecus por UTA) mientras en el otro extremo países como Grecia y Portugal no alcanzan los 5.000. Igualmente, las disparidades son evidentes y favorecen a los países del Norte cuando se relaciona la ayuda en ESP con el VAB a coste de factores, siendo este indicador relativamente bajo en los países del Sur junto con Finlandia y muy elevado en los del Norte superando incluso el 70\%; ello significa que son mucho más dependientes de la asistencia pública que los del Sur en donde el mercado contribuye a generar un porcentaje mayor de la renta agraria. Se puede afirmar por tanto que los países del Sur se encuentran penalizados con respecto a la mayoría de los países del Norte en el trato otorgado por la PAC.

Desde la perspectiva regional, los resultados obtenidos (ver MAPA) permiten poner de manifiesto que existen importantísimas diferencias de protección entre las distintas regiones y que esas diferencias tienden a favorecer a las regiones del Norte. El ESP por UTA supera los 30.000 Ecus sólo en tres regiones, dos francesas y una alemana (Picardie, Lorraine y Mecklenburg-Vorpommern), si el valor lo reducimos a 24.000 lo sobrepasan Bélgica y Dinamarca junto con cinco regiones alemanas, seis francesas y una holandesa. Por el contrario, las que no llegan a 5.000 son 5 regiones portuguesas, 10 griegas 6 españolas, 3 francesas y 11 italianas. De estos datos de deduce con claridad meridiana que la política de ayudas de la PAC no está diseñada para corregir los desequilibrios territoriales. Pero más importante aún que esto es que los Estados miembros del Sur también presentan contrastes importantes entre sus propias regiones como ocurre con nuestro país (volveremos a retomar este aspecto más tarde).

Las presiones externas: la Ronda Uruguay del GATT.

La importancia de esta ronda de negociaciones radica no sólo en el hecho de que se iban a tomar acuerdos que supondrían una mayor liberalización del comercio, sino también, y por eso se aborda aquí, porque por primera vez la agricultura era objeto de atención, hasta llegar a convertirse en uno de los capítulos estrella, en las negociaciones del GATT.

Los Acuerdos alcanzados, de forma muy sintética, son:

- Competencia de las exportaciones: se reducen el volumen de las exportaciones subvencionadas en un $21 \%$, lo mismo que el gasto dedicado a dichas subvenciones en un 36\% de las realizadas durante 1993-94 con res- 
pecto a las de 1986-90.

- Ayuda interna: se reduce globalmente en un 20\% entre 1993 y 1999 y se aceptan las ayudas directas de la PAC que además quedan protegidas por la "cláusula de paz".

- Acceso al mercado: se acepta la arancelización y se disminuyen los derechos de aduana en un 36\% en 6 años (1995-2001). Escalonamiento diferente de la reducción según los países. Además se mantiene la Cláusula de Salvaguardia.

El documento firmado en Marraquech refleja la necesidad de un acuerdo en materia agraria que resolviese el conflicto de intereses que se estaba produciendo en el mercado internacional de productos agrarios durante la década de los 80 como consecuencia del progresivo protagonismo de la CEE como potencia exportadora del sector, especialmente de cereales. Pero además de acuerdo necesario para evitar un conflicto de intereses, éste ha sido visto como la consecuencia lógica de los procesos de liberalización y globalización de la economía mundial, defendida por USA -con bastante cinismo por cierto- como necesaria para favorecer el desarrollo de los países del Tercer Mundo al propiciar la entrada de sus producciones agrarias en los mercados desarrollados, especialmente los europeos. Además, se hacía imposible establecer un límite al gasto presupuestario destinado a financiar la ayuda a la agricultura, evitando el círculo vicioso en que peligraban desembocar las políticas agrarias seguidas por los principales bloques, compitiendo mutuamente no en términos de eficacia productiva sino en apoyos financieros (ver CUADRO $\mathrm{N}^{\mathrm{0}}$ 7).

Un balance desde la Comunidad sobre la negociación debe partir de la constatación de que ambas partes (Comunidad y USA) tuvieron que modificar y ceder en sus planteamientos iniciales. Ha sido necesaria la reforma de la PAC incorporándose los dos requisitos imprescindibles para que la política agraria europea resultase coherente con los principios del acuerdo GATT: por un lado, la reducción sustancial de los precios administrados (lo cual es coherente con la filosofía del desarme arancelario y de las primas a la exportación) y, por otro, la conversión de las ayudas al productor en una transferencia financiada con cargo al presupuesto público y en buena parte "desconectadas" de la producción o, por lo menos, no estimuladoras de la misma.

Las recientes transformaciones del mundo rural.

Además de hs importantes razones ya expuestas, no conviene olvidar a la hora de explicar los recientes cambios acontecidos en la PAC las profundas transformaciones que el mundo rural ha sufrido en los últimos años y que han supuesto verdaderas rupturas según señala B. HERVIEU (1997). En el ámbito poblacional, con la toma de conciencia por parte de los agricultores de que son una minoría más, entre otras, envejecida y en regresión demográfica. A nivel empresarial, con la crisis del modelo de explotación familiar a costa de una agricultura societaria o, alternativamente, de unas explotaciones de servicios. En el ámbito espacial, con el continuo desarraigo de la producción agraria del territorio. A nivel de consumo, con el cuestionamiento de la tradicional función de la agricultura como proveedora de alimentos al desaparecer la necesidad de la seguridad alimentaria como objetivo global de los países desarrollados. A nivel medioambiental, con la progresiva disolución de la agricultura como la actividad mediadora por excelencia 
entre la sociedad y el mundo vegetal y animal a través de la generalización de las técnicas intensivas y de la biotecnología para la producción masiva de alimentos.

\section{UN CAMBIO DE RUMBO EN LA PAC. LA REFORMA DE 1992.}

El primer texto que presenta un planteamiento claro y contundente de los principios que van a desembocar en la reforma de 1992 es la Comunicación presentada por la Comisión (1988) sobre el futuro del mundo rural. En ella se establece que el espacio rural, además de marco de vida y actividad económica, cumple una serie de funciones "indispensables para la conservación del equilibrio ecológico al tiempo que se ha convertido en un lugar privilegiado de reposo y recreo" (p. 15). Si el documento al que hemos hecho referencia con anterioridad realiza una amplia reflexión sobre el mundo rural y su futuro, los presentados por la Comisión en 1991 (COMISIÓN DE LAS COMUNIDADES EUROPEAS 1991a y b) explicitan con claridad meridiana la filosofía, los objetivos y los motivos que debían inspirar la posterior reforma.

\subsection{Las medidas de la reforma.}

La nueva PAC, firmada en 1992 por los Doce a pesar de la presión de las organizaciones agrarias y de las espectaculares manifestaciones en las calles, representa una verdadera ruptura con los principios de la anciana política agrícola. De forma esquemática, las sustantivas alteraciones que introduce son las siguientes:

a) De algún modo y pese a las constantes manifestaciones en contrario, el principio de preferencia comunitaria instaurado en la Conferencia de Stressa desaparece al hacerlo también los prélèvement a cambio de reducidas tarifas arancelarias. Con ello el mercado interior se va progresivamente adaptando a los precios internacionales, más bajos todavía que los comunitarios, provocándose así una mayor apertura del mercado interior.

b) El agricultor y ganadero que antes recibía sus ingresos en razón del precio de sus mercancías, ahora encuentra que una parte sustancial de sus rentas procede de los pagos compensatorios o de las subvenciones del FEOGA.

c) La financiación de los mercados agrarios cambia radicalmente. Antes los precios elevados que se pagaban en el mercado interior se sufragaban por los consumidores y de forma muy reducida por el contribuyente. Ahora los precios son más bajos y son los recursos que nutren las arcas del FEOGA los que aportan a agricultores y ganaderos sus compensaciones.

d) Los elevados y remuneradores precios existentes con anterioridad propiciaron un fuerte proceso de deforestación de tierras para su uso agrícola. Del mismo modo, la obsesión por la máxima producción generó fuertes procesos de degradación medioambiental. La fijación del objetivo de reducción de las producciones y el favorecimiento de la extensificación propician la reducción del suelo agrícola, y con ello la reforestación, así como el mantenimiento del medio ambiente.

e) La nueva PAC genera un proceso de burocratización más allá de lo conocido hasta ese momento, ya que los sistemas de pagos directos exigen un fuerte control y seguimiento que hagan objetivo y veraz el sistema de ayu- 
das. De ahí la necesidad de consagrar recursos humanos y capital en todas las administraciones agrarias de la UE para garantizar un funcionamiento correcto del sistema. El fraude, que siempre ha existido en todas las políticas de la Unión Europea, ahora adquiere una mayor relevancia social.

f) Las Medidas de Acompañamiento se conciben como complemento a los cambios propuestos en las OCM y constan de un programa específico de medidas medioambientales en el sector agrario, la instauración de un programa reforzado para impulsar la repoblación forestal de tierras agrícolas, en segundo lugar, y la introducción de mayores incentivos para la jubilación anticipada, finalmente.

\subsection{Críticas a la reforma de la PAC.}

En los primeros momentos de su puesta en marcha bastantes especialistas hicieron de la reforma en su conjunto una valoración bastante negativa. ESCUDERO ZAMORA (1991) entiende que presenta escasas innovaciones de fondo; para LAMO DE ESPINOSA (1991) es contradictoria y tiene como finalidad sustituir nuestro modelo de apoyo a la agricultura por el de Estados Unidos; carece de visión de futuro, es parcial, asimétrica y convierte a la agricultura en un sector subsidiado, además de ser precipitada, según Carlos TIÓ (1993); SINEROGARCÍA (1991) entiende que mantiene el status quo y no alcanza los objetivos y las expectativas planteadas; MORALEDA QUÍLEZ (1991) proclama reforma sí pero no así; como flagrante violación del Tratado de Roma se cataloga por BALLARÍN MARCIAL (1991); MASSOT MARTÍ (1993) entiende que la reforma sólo puede aspirar a introducir una PAC de transición; como reforma que "no ha ido demasiado lejos ni en la reducción de las diferencias de las rentas agrarias entre las regiones de Europa ni en la integración de los objetivos ambientales en las medidas de política agraria fue calificada por ILBERY (1993); Isabel BENITO (1993) resalta que la reforma no sólo no cumple el objetivo de redistribución de rentas que se propuso sino que incluso lo ataca; supone el cuestionamiento de las figuras sociales del denominado modelo agrario europeo como es el caso del agricultor familiar y profesional eficiente según ARNALTE (1993). Son éstos algunos de los ejemplos que se podrían haber citado.

Los mismos autores que cuestionaron la reforma en su conjunto lo hacen con las ayudas directas (pagos compensatorios) y con las medidas de acompañamiento al ser, sin lugar a dudas, las medidas más importantes de la reforma y, quizás por ello también, las más polémicas. Se entendió que las primeras iban a generar un freno a la reconversión de la agricultura y comprometían toda la estrategia de dinamización del mundo rural, ya que su implantación es psicológicamente desmovilizadora y tecnológicamente regresiva; no van a favorecer el control y gestión de las mismas; van a provocar un incremento de la dualidad del campo europeo; no van a ser capaces de conciliar productividad y solidaridad; es un sistema insostenible como consecuencia de su transparencia en la concesión indiscriminada de las ayudas; es discutible su viabilidad a largo plazo y, en definitiva, estas ayudas convierten al sector en un sector subsidiado.

Las medidas de acompañamiento se cuestionan por el escaso volumen de su asignación presupuestaria; por su carácter cofinanciado y por sus efectos negati- 
vos sobre el mercado de inputs y de tecnología ligados al sector agrario; pero, sobre todo y a nuestro entender, porque la filosofía que subyace en los programas forestales y agroambiental no responde a la realidad de todos los países de la UE sino a la de los no mediterráneos y, lo que es aún más importante, porque los programas medioambientales se fundamentan, entendemos, en un gran contrasentido ya que frente al principio medioambiental por excelencia de "quien contamina paga", se implanta el de pagar para que no se contamine, lo que no deja de ser una incongruencia lo mismo que la de pagar por hacerlo bien. Al agricultor, al igual que a cualquier otro empresario que desarrolle una actividad económica, se le debería exigir que produjera con unos mínimos de respeto al medio ambiente, la superación voluntaria de ellos conllevaría la percepción de ayudas públicas.

Actualmente, transcurridos algunos años desde su puesta en marcha y con la perspectiva que el tiempo ofrece, se pueden valorar algunos de los aspectos positivos y negativos de una reforma que fue inicialmente tan mal catalogada en su conjunto, como hemos tenido ocasión de comprobar.

Sin lugar a dudas, una de las repercusiones más importantes que la reforma está teniendo es la mejora del medio ambiente como consecuencia de la extensificación y de la retirada de tierras de cultivo, lo que ha supuesto una fuerte reducción de excedentes favorecida, sin lugar a dudas, por la sequía sufrida en los países mediterráneos en la primera mitad de los 90. Otro de los aspectos positivos que se consolida con la reforma es una importante estabilidad de las rentas agrarias gracias a las ayudas directas así como su incremento en los últimos años (con el aumento de liquidez consiguiente), máxime cuando es admitido por todos que una parte importante de la agricultura comunitaria (entre ella una gran parte de la española) está, en general, lejos de ser competitiva en el marco que se avecina y que, por tanto, no podría mantenerse únicamente con los precios que pague el mercado. Además, se constata el carácter diverso de las respuestas, o si se quiere mejor estrategias, adoptadas por parte de los empresarios agrarios ante el cambio de escenario sufrido por la PAC, tal y como han señalado en recientes trabajos BARDAJI, I; MORENO, C; RAMOS, E. y RAMOS, F. (1995) y CASTILLO QUERO, M. y MORENO APARICI, C. (1996).

Estas subvenciones o compensaciones son hoy una parte importante de los ingresos agrarios en un país como España (ver CUADRO $\mathrm{N}^{\circ} 8$ ) convirtiéndose en un elemento básico de la renta agraria, sobre todo en una actividad donde la variabilidad climática, especialmente en las zonas mediterráneas, tiene una enorme importancia. Como puede comprobarse (ver CUADRO N ${ }^{\circ}$ 9), su impacto sobre las diferentes regiones españolas resulta muy desigual, pues si bien en algunas CC.AA. en 1994 las subvenciones comunitarias suponían más del 40\% del Valor Añadido Bruto a precios de mercado (Aragón (80\%), Castilla la Mancha (73\%), Castilla y León (52\%), Extremadura (51\%), Andalucía (43\%) y Madrid (42\%)) en otras no llega al 10\% (Galicia, Cantabria, Comunidad Valenciana y Canarias). La España compensada es la del interior junto con Andalucía. La España periférica, con la excepción de Andalucía, carece prácticamente de subvenciones o éstas son muy limitadas. Y la razón es sencilla: dado que la UE alteró las OCMs de los productos continentales, primero, aplazando las de los mediterráneos, y dado que aquéllos son objeto de producción predominante en el interior -y parcialmente en Andalucía- era lógico que las subvenciones llegaran de forma más abundante a ta- 
les zonas de nuestra geografía.

Además, estas ayudas no están generando la desprofesionalización del sector que algunos auguraban, al menos así se ha puesto de manifiesto en las comarcas cerealistas de Castilla y Andalucía que han servido de base a los estudios anteriormente citados, si bien sí han aumentado la resistencia a la jubilación de los agricultores (especialmente los que no tienen continuadores en la explotación) aunque también en las comarcas en las que los resultados económicos son más favorables se está produciendo una importante incorporación de jóvenes a la agricultura. Según SANCHO COMíNS, J. y NAVALPOTRO JiMÉNEZ, P. (1995) el proceso de extensificación agraria incentivado por la PAC favorece la diversificación económica y una cierta disminución de la demanda de UTAs en la actividad agraria, en cierto modo compensada con la primera.

Los que podrían ser denominados "éxitos" de la reforma no deben hacernos minusvalorar, y menos aún olvidar, algunos aspectos "negativos" o, si se quiere mejor, objetivos no cumplidos de la reforma. Entre ellos merece destacarse el hecho de que las diferencias en la protección a los cultivos desincentiva su diversificación llegando incluso a bloquearla completamente; sólo se produce ésta cuando es la vía para obtener unos resultados mejores. Más importancia tiene el hecho de que la reforma no ha mejorado significativamente las diferencias sociales y territoriales en el reparto de los fondos comunitarios y, sobre todo, que haya sido incapaz de mantener la población de muchas áreas rurales (uno de los objetivos que la inspiró) a lo que se añade el carácter cada vez más precario de los asalariados agrícolas. En efecto, el Dictamen del Comité Económico y Social de la UE de 1997 sobre el balance de los tres primeros años de aplicación de la reforma de la PAC señala que en la Europa de los Doce el empleo agrícola se ha reducido en 205.000 empleos entre 1990 y 1995.

Del mismo modo, el apoyo público se ha vuelto mucho más transparente, más explícito, y por ello más contestado socialmente. Muchos sectores de la sociedad se preguntan ahora porqué determinados individuos deben recibir subvenciones públicas tan cuantiosas sin casi contrapartida. La solución a este problema, según GARCÍA AZCÁRATE, T. (1997), debe ser la sustitución del carácter compensatorio de las ayudas establecidas en la reforma de 1992 por el de estar condicionadas (el beneficiario debería cumplir una serie de requisitos rurales, sociales y medioambientales), lo que las haría más defendibles dentro de la sociedad y probablemente alejaría a titulares de explotaciones de carácter especulativo.

Igualmente, se puede señalar, tal y como lo hace BARAJA, E. y MOLINERO, F. (1996), que la reforma de la PAC ha contribuido a que no se produzca un necesario ajuste estructural en las explotaciones agrarias, aunque de ello no sea la única responsable. La nueva PAC ofrece la posibilidad de obtener rentas con mínimo esfuerzo y sin apenas riesgos; de ello se ha derivado el mantenimiento de un tipo de explotación marginal (jubilados, no profesionales, etc.) que, a la par, incide en otro de los capítulos de la reestructuración como es el del mercado de la tierra y el de los arrendamientos. 


\section{LA AGENDA 2.000 Y LOS RETOS DE LA PAC ANTE EL PRÓXIMO SIGLO.}

\subsection{La Agenda 2.000. De las propuestas de la Comisión a lo aprobado en la Cumbre de Berlín.}

La filosofía continuista que inspira la Agenda 2.000 (COMISIÓN DE LA COMUNIDADES EUROPEAS 1997b) ya fue recogida en el informe sobre estrategia agraria redactado en 1995 por el Comisario de Agricultura en el que se plantea como opción la de profundizar en la línea de reforma llevada a cabo por MacSharry (COMISIÓN DE LA COMUNIDADES EUROPEAS 1995). Ello conlleva la formulación de nuevos objetivos. En primer lugar, la necesidad de incrementar la competitividad en la medida en que los precios comunitarios se van a ir acercando a los mundiales, será por tanto el mercado el que oriente el sector agrario pero manteniendo los pagos compensatorios; en segundo lugar, el apoyo al mundo rural a través de ayudas a los habitantes de estas zonas que produzcan bienes o servicios medioambientales, se plantea por tanto la necesidad de desarrollar lo que el documento denomina como política rural integrada y, finalmente, la simplificación de los procedimientos y el reforzamiento del principio de subsidariedad lo que implica el reforzamiento de los mecanismos "de abajo a arriba", tal y como ya se utilizan en los programas Leader. Pero las ideas más novedosas, aunque escasamente desarrolladas, que introduce el documento son, de un lado, la necesidad de limitar las ayudas a un máximo individual modulándolas por parte de los distintos Estados miembros sobre la base de unas normas acordadas en común y, de otro, la de condicionar su percepción al cumplimiento de ciertos requisitos de carácter medioambiental.

La propuesta que realiza la Comisión en materia agraria puede ser calificada como claramente continuista, abiertamente conservadora con el camino iniciado en 1992 y perjudicial para las rentas agrarias. Continuista porque, pese a las declaraciones sobre la necesidad de transformar la PAC en una política de base territorial, las medidas para que se produzca dicha transformación son nulas. Se mantienen las ayudas a las rentas dependientes de los niveles de producción sin modulación alguna lo que no favorece, como actualmente está ocurriendo, la integración social y espacial de las regiones agrarias europeas. Se siguen manteniendo dos políticas diferentes para el desarrollo de las zonas rurales: las actuaciones de carácter sectorial dependientes del FEOGA y las acciones de desarrollo rural enmarcadas dentro del FEDER. Conservadora porque no se introducen novedades de facto de cara al creciente proceso de globalización de los mercados y a la progresiva pérdida de legitimidad social del apoyo público a una producción excedentaria e intensiva, acaparada en pocas manos y desligada del territorio. Por último, es claramente perjudicial para las rentas agrarias desde el momento en que los descensos en los precios de mercado no se compensan íntegramente con el incremento de las ayudas a la renta.

La Cumbre de Berlín puso de manifiesto tanto la austeridad presupuestaria que ya se observaba en la propuesta Santer como las tensiones desintegradoras que se vienen observando, cada vez con mayor fuerza, en el seno de la UE. Como acertadamente declarara al diario El País el Jefe de Gobierno luxemburgués 
Jean-Claude Juncker, "en esta Cumbre sólo hay vencedores nacionales y una víctima europea". Además, ha dejado sin resolver algunas de las grandes interrogantes que se ciernen sobre la UE, especialmente en materia agraria que es lo que aquí nos ocupa, como son la modulación de las ayudas, la reforma de la OCM de los productos lácteos y ha rebajado algunas de las actuaciones tendentes a liberalizar el sector propuestas por la Comisión (quizás la proximidad de las elecciones europeas haya tenido mucho que ver en estas decisiones). Estamos, por tanto, muy alejados de la afirmación según la cual lo aprobado constituye la "reforma más ambiciosa y profunda jamás realizada en la Política Agraria Comunitaria" como declarara F. Fischler o "el cambio más importante desde la reforma de la PAC", según Loyola de Palacio (El País 19-IX-1999).

\subsection{Los retos de la PAC en el contexto del próximo siglo.}

La creciente liberalización del comercio y la necesidad de mayor competitividad.

La UE se enfrenta en la actualidad al imposible reto de conjugar un juego más competitivo de las fuerzas del mercado y la reducción de las desigualdades económicas y sociales dentro de su territorio. Una economía cada vez más globalizada y abierta supondrá el enfrentamiento tanto con países más competitivos como UsA como con países subdesarrollados con menores costes de producción como consecuencia del dumping social y medioambiental que definen sus economías.

La nueva ronda de negociaciones de la OMC que ha tenido lugar en Seattle (Whasington) pretendía imponer nuevas cotas de liberalización comercial. En materia agraria se traducía no sólo en una rebaja, cuando no la abolición, de las subvenciones a la exportación y de las trabas a la importación sino también en el cuestionamiento de algunas ayudas a la producción como los pagos compensatorios. La oposición social en la calle, el conflicto de intereses que enfrenta a USA y UE (en temas tan importantes como la protección de la agricultura, los productos transgénicos o la propiedad intelectual y cultural), a los países desarrollados con los que lo no están (por cuestiones relacionadas con los derechos laborales), sin olvidar la necesidad de mostrar una postura de fuerza frente a la UE por parte de Bill Clinton y del Partido Demócrata ante la inminencia del proceso electoral norteamericano, han provocado el fracaso más absoluto de la actual Ronda de negociaciones. La discusión de estos objetivos no ha terminado, se ha aplazado y trasladado a Ginebra.

Por otra parte, la aplicación de la actual PAC a los países del Centro y Este de Europa plantea serios problemas. Quizás el menos grave de todos sea el presupuestario. Los mayores se derivan del elevado precio de los productos agrarios vigente en la UE que de implantarse conllevaría una importante elevación del coste de la vida en estos países; de los controles de la oferta en países fuertemente agrarios especializados en producciones ya excedentarias en la actual Unión Europea y, por último, de los pagos compensatorios a los que no tendrían derecho en la medida en que a ellos no se les puede compensar por nada pero que sería inadmisible que no los cobraran frente a agricultores europeos más ricos que sí los percibirían.

Finalmente, el denominado Acuerdo de Barcelona suscrito con los países del 
denominado frente Sur de la UE (ante la necesidad de contribuir a la paz, la estabilidad y la seguridad del Mediterráneo) ha supuesto el aumento progresivo de las cuotas de importación de productos mediterráneos a cambio de aceptar importaciones de productos europeos continentales como son los cereales, carne y productos lácteos. En esta misma línea se encuentra la necesidad de negociar un nuevo acuerdo con los Estados firmantes del Convenio de Lomé de 1975 (países ACP) cuya renovación finaliza en el año 2000 o las conversaciones con los países que forma el Mercosur y Chile que pueden finalizar en el 2005.

Las presiones internas. Más Europa frente a menos Europa.

La UE se debate "entre la cohesión y la desintegración", como bien ha titulado Lázaro ARAUJO (1998) un reciente artículo. Este hecho se ha percibido en las últimas grandes cuestiones políticas que se han abordado en el seno de la UE. En efecto, en las negociaciones del Tratado de Amsterdam (16-17 de junio de 1997) se cuestionaron tanto los objetivos de cohesión acordados en el Tratado de Maastricht como el proceso de integración por parte de países como Francia, Alemania y el Reino Unido; el debate se resucitó en el Consejo Europeo de Cardiff en junio de 1998. En él H. Kohl y J. Chirac plantearon la necesidad de deslindar de manera clara las competencias de la UE y las de los Estados miembros invocando la "legitimidad democrática" para que la UE "devolviera" sus poderes a los Estados y regiones. Plantean la necesidad de mantener la austeridad presupuestaria y de establecer esquemas de núcleo duro, de diferenciación o de geometría variable, ante una Europa cada vez más heterogénea que requiere más fondos de solidaridad y una mayor dificultad en su gestión. Este claro enfrentamiento entre los países que desean más y menos Europa se refleja en dos episodios claramente perceptibles. De un lado, la lucha contra las Instituciones que consagran el mayor grado de gestión comunitaria como son la Comisión y el Tribunal de Justicia. De otro, el debate sobre el sistema financiero de la UE con propuestas como la cofinanciación estatal del $25 \%$ de las ayudas directas pagadas a los agricultores.

La necesaria búsqueda de la calidad: el disfrute del medio ambiente y de alimentos saludables.

Además de presiones externas e internas, la PAC del futuro se enfrenta a un gran reto global que es la búsqueda de la calidad frente a la cantidad de sus producciones. Búsqueda de calidad que repercute directamente, al menos, en dos cuestiones fundamentales: en el mantenimiento del medio ambiente a través de prácticas agrarias basadas en la sostenibilidad y en la producción de alimentos saludables. Desafíos precipitados por los recientes y graves acontecimientos ocurridos como el de las "vacas locas" -inicialmente británicas hoy europeas-, el de la contaminación por dioxinas de pollos y cerdos belgas o el de fungicidas de la Coca-Cola.

Para dar respuesta a esta creciente inquietud, la UE ha elaborado un Libro Verde (COMISIÓN DE LAS COMUNIDADES EUROPEAS, 1997c) y una Comunicación (COMISIÓN DE LAS COMUNIDADES EUROPEAS, 1997d) en defensa de la salud del consumidor. El objetivo fundamental de dicha normativa no es otro que el de reforzar la protección de la salud del consumidor como requisito previo y necesario. También es importante proteger el bienestar y el cuidado de los animales y las plantas. Los principios generales en los que se basará la política agraria alimentaria serán: la separación de la responsabilidad legislativa de la consulta cientí- 
fica así como de la inspección; una mayor transparencia en los procesos de toma de decisiones y de inspección y, sobre todo, la aplicación estricta del principio de precaución en los casos de incertidumbre científica.

Ahora bien, estas medidas de control sanitario y fitosanitario de las producciones en defensa de la salud de los consumidores no sólo han generado importantes enfrentamientos comerciales entre las distintas potencias agrarias (caso de la carne de vacuno hormonada entre USA y la UE) sino que se incrementarán en el futuro (productos transgénicos). Ello es así en la medida en que este tipo de medidas encuentra difícil acomodo dentro de la filosofía liberalizadora y de libre comercio impuesta por la OMC, sin olvidar su utilización por los diferentes Estados como una argucia neoproteccionista capaz de paralizar el multilateralismo agrario.

La respuesta a todos estos escándalos no ha sido otra que el constante crecimiento de las producciones de carácter ecológico, como lo demuestra el incremento del $40 \%$ anual que han sufrido en Europa en los últimos años.

La necesidad de convertir la PAC en PARC.

Todos estos procesos internos y externos conllevan necesariamente el final de la etapa agro-sectorial que supone la P AC basada en el productivismo agrícola. La cuestión clave a responder ahora desde una perspectiva comunitaria es si la conclusión de esta etapa ha de desembocar en la desaparición de cualquier política supranacional, en su concepción y financiación, a favor de la agricultura y el mundo rural o si, por el contrario, son posibles nuevos paradigmas que permitan edificar una política sustitutiva de la PAC que se adecue a los cambios que se están produciendo tanto interna como externamente al sector agrario.

A nuestro entender, lejos de aquéllos que defienden que mantener una política en el sector es algo ya superado, mantenemos lo contrario. La nueva política para el mundo rural, superadora de los actuales planteamientos sectoriales, debe ser "regionalizada, de carácter territorial, activa, selectiva e integrada" (SOTTE, 1996: 155); debe ir orientada hacia el desarrollo rural integrado. Es necesario imbricar la dimensión socio-rural y la medioambiental a la tradicional componente agroproductiva de las políticas públicas en materia rural. Ello supone asumir tanto que el sector agrario, hoy por hoy, es insustituible dentro de la vida económica de las zonas rurales como que es necesaria la diversificación de sus actividades productivas.

Esta filosofía ruralista que debe imbuir la nueva política agraria y rural comunitaria tiene que asumir tanto la necesidad de ayudas para su desarrollo como su adecuación a las distintas realidades rurales de la UE; el mundo rural y la política que a él se destine debe ser entendida como un asunto territorial. Entendemos que las ayudas tendrían que ser establecidas como complementos a la renta agraria, bien por la falta de competitividad de las explotaciones bien por la producción de bienes y servicios; estar desconectadas de la producción (lo que no ocurre actualmente); condicionadas al cumplimiento de ciertas prácticas agrarias durante un tiempo determinado; limitadas a un máximo de ayuda por titular y moduladas en función de criterios extraproductivos de carácter social. Sólo de esta manera se podrá conseguir que sean aceptadas dentro de las normas establecidas por la OMC $\mathrm{y}$, sobre todo, asumidas por la sociedad que debe financiarlas. 


\section{UNA REFLEXIÓN FINAL.}

La PAC está compuesta por una amalgama de instrumentos que comportan distorsiones entre productos. El que una región se vea beneficiada por ella depende, en gran medida, del grado de adaptación de su estructura productiva a la de las distorsiones de dicha política. Esto tiene poco que ver con la cohesión económica y social y más bien convierte la distribución de los beneficios de la PAC en una especie de lotería entre agricultores y territorios.

Igualmente, no conviene olvidar que la actual PAC reformada sigue siendo la principal defensa comercial y financiera contra las consecuencias negativas de una liberalización sin medida de los mercados agrarios. Una política que, no ha de olvidarse, continúa siendo proteccionista, desconectando aún casi todos los precios de los mercados mundiales y que sigue apoyando las rentas de los agricultores a unos niveles que las Administraciones nacionales serían incapaces de garantizar. Sigue teniendo muchos detractores, se enfrenta a innumerables retos y, necesariamente, deberá seguir evolucionando y modificándose.

\section{BIBLIOGRAFÍA CITADA.}

- ANDRÉS, R. DE Y URZAINQUI, E. (1995): «Comercio internacional agrario, GATT y desarrollo sustentable», en: CADENAS MARÍN, A. (Coord). Agricultura $y$ desarrollo sostenible, Madrid. Secretaría General Técnica del MAPA

- ARNALTE ALEGRE, E. (1993): «Modelo productivo de la agricultura europea y la reforma de la política agrícola común», en: AA.VV.: Agricultura y políticas agrarias en el Sur de Europa, Madrid. Servicio de Publicaciones del MAPA. pp. 277-289.

- BALlARÍN MARCIAL, A. (1991): «La agricultura española y la nueva PAC . La cuestión sobre la legalidad de la reforma», Derecho Agrario y Alimentario, Núm. 17. pp 68-75.

- BARAJA, E. y MOLINERO, F. (1996): «El significado de la PAC en España», Primer Simposium de Geógrafos Rurales Británicos y Españoles, Madrid. Ed. AGE. pp. 57-69

- BARDAJI, I.; MORENO, C.; RAMOS, E. Y RAMOS, F. (1995): «Estrategias de respuesta en las explotaciones cerealistas de secano ante la nueva política agrícola», Revista Española de Economía Agraria, n 173. pp. 9-30.

- BENITO, I. (1993).: «Interrogantes tras la reforma de la PAC», en: AA.VV. Agriculturas y políticas agrarias en el Sur de Europa, Madrid. MAPA. pp. 249254.

- CASTILlo QUeRo, M. Y MORENO APARICI, C. (1996): «Respuesta diferencial de los cultivadores cerealistas a la reforma de la PAC en algunas comarcas de Castilla y León», Revista Española de Economía Agraria, no 178. pp. 193-229.

- COMISIÓN DE LAS COMUNIDADES EUROPEAS (Varios años): La situación de la Agricultura en la Comunidad, Bruselas.

- COMISIÓN DE LAS COMUNIDADES EUROPEAS, (1988): El futuro del mundo rural, Bruselas. Oficina de Publicaciones Oficiales de las Comunidades Europeas.

- COMISIÓN DE LAS COMUNIDADES EUROPEAS (1991a): Evolución y futuro de la P AC. Documento de reflexión de la Comisión, COM (91). 100 final de 1 de 
febrero de 1991.

- COMISIÓN DE LAS COMUNIDADES EUROPEAS. (1991b): Desarrollo y futuro de la Política Agraria Común. Continuación del documento de reflexión, COM (91) 258 final de 19 de julio.

- COMISIÓN DE LAS COMUNIDADES EUROPEAS. (1995): Estudio sobre estrategias alternativas para el establecimiento de relaciones en materia de agricultura entre la Unión Europea y los países asociados con vistas a la futura adhesión de estos últimos, (Dicho estudio fue elaborado por el Sr Fischler en acuerdo con el Sr. Van Der Brock). Publicado en la Revista Española de Economía Agraria, $\mathrm{n}^{\circ}$ 176-177. pp. 305-354.

- COMISIÓN DE LAS COMUNIDADES EUROPEAS. (1997a): Estudio de impacto de las concesiones a los países. Mediterráneos, COM(97) 477. Final. Bruselas 1-10-1997.

- COMisión De Las Comunidades EuROPEAS. (1997b): La Agenda 2.000. Por una unión más fuerte y amplia, Bruselas 17-07-1997. (DOC /97/7).

- COMISIÓN DE LAS COMUNIDADES EUROPEAS. (1997c): Los principios generales de la legislación alimentaria de la UE (Libro Verde de la Comisión), $\operatorname{COM}(97) 176$ final.

- COMISIÓN De LAS COMUNIDADES EUROPEAS. (1997d): Salud del consumidor y seguridad alimentaria, $\operatorname{COM(97)~} 183$ final de 30-4-1997.

- COMISIÓN De LAS COMUNIDADES EUROPEAS. (1999): Vademécum Presupuestario de 1998, Bruselas.

- ESCUDERO ZAMORA, G. (1991): «La reforma de la PAC», Revista de Estudios Agro-Sociales, $\mathrm{n}^{\circ}$ 156. pp. 17-39.

- GARCÍA ÁlVAREZ-COQUE, J.M.: (1998): Memoria para la obtención de la Cátedra de Universidad. Mecanografiada.

- GARCÍA AZCÁRATE, T. (1997): «La reforma de la PAC y la agricultura familiar en España», en: BRETÓN SOLO DE ZALDIVAR, V. Y OTROS (Coords): $L a$ agricultura familiar en España, pp. 129-134

- HeRviEU, B. (1997): Los campos del futuro. Madrid. MAPA.

- ILBERY, B.W. (1993): «La agricultura de Europa Occidental y la reforma de la PAC», en: AA.VV. Agriculturas y políticas agrarias en el Sur de Europa. Madrid. MAPA. pp. 165-180.

- LAMO DE ESPINOSA, J. (1991): «Reflexiones críticas sobre la nueva PAC». Revista de Estudios Agro-Sociales, Núm. 156. pp. 67-83.

- LÁzARo ARAujo, L. (1998): «La Unión Europea, entre la cohesión y la desintegración», Política Exterior, nº 68. pp. 81-95.

- MAPA. (Subdirección General de Estadística y Análisis Regional). (1996): Evolución de macromagnitudes agrarias regionales. 1985-1994, MAPA. Madrid.

- MAPA (Subdirección General de Estadística.) (1999): Macromagnitudes del Sector Agrario. 1998, MAPA. Madrid.

- MASSOT MARTÍ, A. (1993): «La transición hacia una nueva PAC y un nuevo derecho agrario en la perspectiva de la unión económica y monetaria», Noticias de la CEE, Núm. 97. pp. 43-57.

- Molinero HeRnANDO, F. (1990): Los espacios rurales. Barcelona. Ariel Geografía. 
- MoRALEDA Quílez, F. (1991): «La reforma de la PAC en la perspectiva de los mejores ingresos y el bienestar de los agricultores. Reforma sí pero no así»,, Revista de Estudios Agro-Sociales, Núm. 156. pp. 185-206.

- SANCHO COMÍNS, J. Y NAVALPOTRO JIMÉNEZ, P. (1995): «La extensificación de los secanos herbáceos españoles: efectos territoriales y sociales de la nueva PAC de la Unión Europea», Estudios Geográficos, Núm. 221. pp. 737-759.

- SINERO GARCÍA, F. (1991): «La reforma de la PAC y los equilibrios territoriales», Revista de Estudios Agro-Sociales, $\mathrm{n}^{\mathrm{o}}$ 156. pp. 105-125.

- SotTE, F. (1996): «La dimensión regional de una nueva PAC orientada al desarrollo rural integrado», Revista Española de Economía Agraria, Núm 176-7. pp. 145-165.

- TIÓ SARALEgUI, C. (1993): «Crítica de la Reforma de la PAC», Información Comercial Española, no 720-1. pp. 19-29.

\section{ANEXO ESTADÍSTICO Y CARTOGRÁFICO.}

CUADRO $\mathrm{N}^{\circ} 1$. Cantidad y valor de los productos objeto de almacenamiento público.

\begin{tabular}{|c|c|c|c|c|c|c|}
\hline \multirow[b]{2}{*}{ Productos } & \multicolumn{3}{|c|}{1985} & \multicolumn{3}{|c|}{1996} \\
\hline & $1.000 \mathrm{Tm}$ & Mecus & Mecus (\%) & $1.000 \mathrm{Tm}$ & Mecus & $\begin{array}{c}\text { Mecus } \\
(\%)\end{array}$ \\
\hline Trigo blando & $11.902,7$ & $2.390,3$ & 22,6 & 304,3 & 31,5 & 5,7 \\
\hline Trigo duro & 986,2 & 264,2 & 2,5 & 55,8 & 2,8 & 0,5 \\
\hline Cebada & $4.650,7$ & 940,5 & 8,9 & 315,3 & 25,9 & 4,7 \\
\hline Centeno & $1.108,2$ & 225,7 & 2,1 & 498,0 & 35,1 & 6,4 \\
\hline Azúcar & 0,00 & 0,00 & 0,0 & 0,00 & 0,00 & 0,0 \\
\hline Ac. Oliva & 75,4 & 115,6 & 1,1 & 12,4 & 7,5 & 1,4 \\
\hline Colza & 0,00 & 0,00 & 0,0 & 0,00 & 0,00 & 0,0 \\
\hline Girasol & 0,00 & 0,00 & 0,0 & 0,00 & 0,00 & 0,0 \\
\hline Tabaco & 14,7 & 14,5 & 0,1 & 0,1 & 0,1 & 0,0 \\
\hline Leche & 513,8 & 866,7 & 8,2 & 124,7 & 106,9 & 19,3 \\
\hline Mantequilla & $1.018,1$ & $3.415,7$ & 32,3 & 39,3 & 43,2 & 7,8 \\
\hline C. bovino & 818,3 & $2.270,2$ & 21,5 & 433,6 & 294,7 & 53,3 \\
\hline C. porcino & 25,8 & 28,9 & 0,3 & 0,00 & 0,00 & 0,0 \\
\hline Otros & & 47,3 & 0,4 & 872,6 & 4,8 & 0,9 \\
\hline Total & & $10.579,8$ & 100,0 & & 552,5 & 100,0 \\
\hline$F_{\text {I }}$ & & dades & & & Elab & n pro- \\
\hline
\end{tabular}


CUADRO $\mathrm{N}^{0}$ 2. Evolución de los gastos comunitarios. (ejecución en pagos). (Mecus).

\begin{tabular}{lrrrrrrrrr}
\hline \multicolumn{1}{c}{ Ambitos } & $\mathbf{1 9 6 0}$ & $\mathbf{1 9 6 5}$ & $\mathbf{1 9 7 0}$ & $\mathbf{1 9 7 5}$ & $\mathbf{1 9 8 0}$ & $\mathbf{1 9 8 5}$ & $\mathbf{1 9 9 0}$ & $\mathbf{1 9 9 5}$ & $\mathbf{1 9 9 9 *}$ \\
\hline FEOGA-G & 0 & 29 & 3.108 & 4.328 & 11.292 & 19.728 & 25.605 & 34.490 & 40.940 \\
FEOGA-O & 0 & 5 & 58 & 77 & 315 & 686 & 1.825 & 2.531 & 3.852 \\
PAC & 0 & 34 & 3.166 & 4.405 & 11.607 & 20.414 & 27.430 & 37.021 & 44.792 \\
FEDER & 0 & 0 & 0 & 150 & 793 & 1.610 & 4.554 & 8.373 & 12.965 \\
FSE & 0 & 0 & 37 & 149 & 701 & 1.407 & 3.212 & 4.547 & 7.396 \\
F. Cohesión & 0 & 0 & 0 & 0 & 0 & 0 & 0 & 1.699 & 2.877 \\
IFOP & 0 & 0 & 0 & 0 & 0 & 0 & 0 & 248 & 492 \\
Investigac. & 0 & 0 & 63 & 116 & 364 & 678 & 1.790 & 2.478 & 3.056 \\
A.Exterior. & 0 & 0 & 1 & 251 & 604 & 964 & 1.431 & 3.406 & 4.591 \\
Administr. & 21 & 43 & 115 & 364 & 830 & 1.305 & 2.333 & 3.870 & 4.435 \\
Reembolsos & 0 & & 2 & 383 & 959 & 1.490 & 3.313 & 3.079 & 2.152 \\
\hline Total & 21 & 77 & 3.385 & 5.817 & 15.857 & 27.867 & 44.063 & 66.547 & 86.350 \\
\hline
\end{tabular}

FUENTE: COMISIÓN DE LAS COMUNIDADES EUROPEAS (1.999). Elaboración propia.*Avance.

CUADRO N ${ }^{0}$ 3.a. Ayudas comunitarias según producciones. (Mecus, 1985).

\begin{tabular}{|c|c|c|c|c|c|c|}
\hline \multirow{2}{*}{ Productos } & \multirow{2}{*}{ Créditos } & \multirow{2}{*}{ Restitu. } & \multirow{2}{*}{ Ay. compen } & \multicolumn{2}{|c|}{ Total } & \multirow{2}{*}{$\%$ PFA } \\
\hline & & & & Mecus & $\%$ & \\
\hline Herbáceos & $3.793,3$ & $1.080,1$ & $1.961,0$ & $6.834,4$ & 20,3 & 13,8 \\
\hline Azúcar & $1.804,5$ & $1.352,8$ & 11,6 & $3.168,9$ & 9,4 & 2,5 \\
\hline Ac. Oliva & 692,2 & 19,2 & 667,8 & $1.379,2$ & 4,1 & 1,3 \\
\hline Algodón & 212,0 & 0,0 & 212,7 & 424,7 & 1,3 & 0,4 \\
\hline Frut-hort & $1.230,7$ & 74,5 & 942,8 & $2.248,0$ & 6,7 & 13,7 \\
\hline Vino & 921,4 & 18,9 & 213,9 & $1.154,2$ & 3,4 & 4,7 \\
\hline Tabaco & 862,9 & 32,0 & 819,0 & $1.713,9$ & 5,1 & 0,7 \\
\hline Arroz & 50,1 & 36,6 & 13,5 & 100,2 & 0,3 & 0,3 \\
\hline Leche & $5.933,2$ & $2.028,2$ & $1.891,0$ & $9.852,4$ & 29,3 & 19,2 \\
\hline C. Vacuno & $2.745,8$ & $1.338,6$ & 196,5 & $4.280,9$ & 12,7 & 14,1 \\
\hline C. Ovino & 502,4 & 0,0 & 502,4 & $1.004,8$ & 3,0 & 1,7 \\
\hline Tot. Medit. & $4.471,7$ & 181,2 & $3.372,1$ & $8.025,0$ & 23,9 & 22,8 \\
\hline Tot. Conti & $14.276,8$ & $5.799,7$ & $4.060,1$ & $24.136,6$ & 71,8 & 49,6 \\
\hline Tot. Gastos & $19.517,2$ & $6.587,7$ & $7.515,6$ & $33.620,5$ & 100,0 & 100,0 \\
\hline
\end{tabular}

FUENTE: COMISIÓN DE LA COMUNIDADES EUROPEAS. (Varios años). Elaboración propia.

CUADRO N ${ }^{\circ}$ 3.b. Ayudas comunitarias según producciones. (Mecus (1996).

\begin{tabular}{lrrrrrr}
\hline \multicolumn{1}{c}{ Productos } & \multirow{2}{*}{ Créditos } & \multirow{2}{*}{ Restitu. } & \multirow{2}{*}{ Ay. compen } & \multicolumn{2}{c}{ Total } & \multirow{2}{*}{ \% PFA } \\
& & & & \multicolumn{1}{c}{ Mecus } & \% & \\
Herbáceos & $16.998,0$ & 368,0 & $16.570,0$ & $33.936,0$ & 44,8 & 9,8 \\
Azúcar & $1.843,0$ & $1.344,0$ & 106,0 & $3.293,0$ & 4,3 & 2,4 \\
Ac. Oliva & $2.113,0$ & 44,0 & $2.059,0$ & $4.216,0$ & 5,6 & 1,7 \\
Algodón & 747,0 & 0,0 & 747,0 & $1.494,0$ & 2,0 & 0,6 \\
Frut-hort & $1.557,0$ & 97,0 & $1.076,5$ & $2.730,5$ & 3,6 & 15,7 \\
Vino & 805,0 & 50,0 & 160,0 & $1.015,0$ & 1,3 & 6,4 \\
Tabaco & $1.043,0$ & 4,0 & $1.026,0$ & $2.073,0$ & 2,7 & 0,3 \\
Arroz & 30,0 & 28,0 & 2,0 & 60,0 & 0,1 & 0,5 \\
\hline Leche & $3.718,0$ & $1.703,0$ & $1.501,0$ & $6.922,0$ & 9,1 & 17,5 \\
C. Vacuno & $6.744,0$ & $1.794,0$ & $4.264,0$ & $12.802,0$ & 16,9 & 9,8 \\
C. Ovino & $1.447,0$ & 0,0 & $1.443,0$ & $2.890,0$ & 3,8 & 2,0 \\
\hline Tot. Medit. & $7.742,0$ & 223,0 & $6.513,5$ & $14.478,5$ & 19,1 & 27,2 \\
\hline Tot. Conti & $29.303,0$ & $5.209,0$ & $22.441,0$ & $56.953,0$ & 75,1 & 39,5 \\
\hline Tot. Gastos & $39.443,0$ & $6.299,0$ & $30.083,1$ & $75.825,1$ & 100,0 & 100,0 \\
\hline
\end{tabular}

FUENTE: COMISIÓN DE LA COMUNIDADES EUROPEAS. (Varios años). Elaboración propia. 
CUAdRo No 4. Equivalente de Subsidio a la Producción (ESP) en la Unión Europea. 1995.

\begin{tabular}{|c|c|c|c|c|}
\hline Productos & $\begin{array}{l}\text { Esp total en } \\
\text { Mecus (1) }\end{array}$ & $\begin{array}{l}\text { VAB a p.m. } \\
\text { en M ecus (2) }\end{array}$ & $(1) /(2) * 100$ & $\begin{array}{l}\text { Apoyo al precio } \\
\text { como \% de EsP }\end{array}$ \\
\hline & \multicolumn{4}{|c|}{ Continentales } \\
\hline Trigo & 7.745 & 10.659 & 72,7 & 16,0 \\
\hline Maíz & 2.532 & 4.125 & 61,4 & 52,3 \\
\hline Otros cereales & 6.295 & 5.570 & 113,0 & 30,2 \\
\hline Oleaginosas & 2.454 & 3.472 & 70,1 & 0 \\
\hline Azúcar & 2.682 & 3.529 & 76,0 & 100,0 \\
\hline Leche & 20.052 & 20.174 & 90,4 & 88,0 \\
\hline C. Ovino & 3.358 & 5.355 & 62,7 & 32,8 \\
\hline C. Vacuno & 18.195 & 13.643 & 133,4 & 79,7 \\
\hline C. Porcino & 1.739 & 4.774 & 36,4 & 79,9 \\
\hline \multirow{2}{*}{ Aves y Huevos } & 1.980 & 3.690 & 53,7 & 76,3 \\
\hline & \multicolumn{4}{|c|}{ Productos Mediterráneos } \\
\hline Frutas & 741 & 10.673 & 6,9 & 55,6 \\
\hline Hortalizas & 1.734 & 11.581 & 15,0 & 63,7 \\
\hline A. Oliva & 1.217 & 3.664 & 33,2 & 31,4 \\
\hline Vino & 1.435 & 10.408 & 13,8 & 43,3 \\
\hline Arroz & 496 & 468 & 106,0 & 94,1 \\
\hline Tabaco & 993 & 588 & 168,9 & 0 \\
\hline Algodón & 797 & nd & & \\
\hline Total del grupo (C y M) & 74.445 & 112.373 & 66,2 & \\
\hline
\end{tabular}

Fuente: García Álvarez-Coque, J.M. (1998).

CUADRO N ${ }^{0}$ 5. Gastos de FEOGa-G en los países del Sur según producciones. 1995. (Mecus).

\begin{tabular}{lrrrrrrr}
\hline \multicolumn{1}{c}{ Productos } & Grecia & Italia & Portugal & España & P. Sur & UE-12 & (\%) Sur \\
\hline Cereales y Oleaginosas & 386 & 1.474 & 237 & 2.290 & 4.387 & 15.018 & 29,2 \\
Arroz & 0 & 47 & 1 & 1 & 49 & 50 & 99,2 \\
Azúcar & 7 & 92 & 6 & 70 & 175 & 1.831 & 9,5 \\
A. Oliva & 98 & 477 & 21 & 198 & 793 & 813 & 97,6 \\
Algodón & 740 & 0 & 0 & 58 & 797 & 797 & 100,0 \\
Frutas-Horta. frescas & 279 & 227 & 17 & 362 & 885 & 1.181 & 74,9 \\
Frutas-Horta. Transfor. & 217 & 219 & 58 & 86 & 579 & 653 & 88,7 \\
Vino & 31 & 357 & 26 & 216 & 630 & 858 & 73,5 \\
Tabaco & 411 & 332 & 13 & 126 & 882 & 993 & 88,8 \\
\hline Lácteos & 5 & 177 & 54 & 46 & 282 & 4.029 & 7,0 \\
C. Vacuno & 29 & 138 & 67 & 248 & 482 & 4.021 & 12,0 \\
Ovino-Caprino & 159 & 181 & 52 & 557 & 949 & 1.781 & 53,3 \\
Porcino-Aves-Huevos & 1 & 6 & 3 & 11 & 20 & 344 & 5,9 \\
\hline Otros & 32 & 49 & 44 & 280 & 404 & 921 & 43,9 \\
\hline P. Mediterráneos & 1.783 & 1.659 & 136 & 1.047 & 4.615 & 5.395 & 85,5 \\
\hline Todos productos & 2.394 & 3.774 & 600 & 4.546 & 11.314 & 33.288 & 34,0 \\
\hline \% Mediterráneos & 74,5 & 44,0 & 22,7 & 23,0 & 40,8 & 16,0 & \\
\hline FUENTE: CoMSON & & & &
\end{tabular}

FuENTE: COMISIÓN DE LAS COMUNIDADES EUROPEAS. (1997a). Elaboración propia. 
CUADRO N ${ }^{\circ}$ 6. Distribución nacional del EsP de la Unión Europea entre sus Estados miembros. 1995.

\begin{tabular}{|c|c|c|c|c|c|c|c|}
\hline \multirow{2}{*}{\multicolumn{2}{|c|}{ Países }} & \multirow[t]{2}{*}{ PFA \% } & \multicolumn{2}{|c|}{ EsP Total } & \multirow[t]{2}{*}{ EsP/UTA } & \multirow[t]{2}{*}{ Esp/Ha. } & \multirow[t]{2}{*}{$\begin{array}{l}\text { EsP como } \\
\% \text { del VAB } \\
\text { a c.f. }\end{array}$} \\
\hline & & & Mecus & $\%$ & & & \\
\hline \multicolumn{2}{|l|}{ Portugal } & 1,62 & 1.039 & 1,40 & 1.777 & 212 & 36 \\
\hline \multicolumn{2}{|l|}{ España } & 11,33 & 6.982 & 9,38 & 6.416 & 204 & 41 \\
\hline \multicolumn{2}{|l|}{ Grecia } & 4,21 & 2.740 & 3,68 & 4.443 & 511 & 35 \\
\hline \multicolumn{2}{|l|}{ Italia } & 15,64 & 10.413 & 13,99 & 5.982 & 611 & 40 \\
\hline \multicolumn{2}{|l|}{ Irlanda } & 2,07 & 2.482 & 3,33 & 11.184 & 560 & 76 \\
\hline \multicolumn{2}{|l|}{ Bélgica-Lux. } & 3,29 & 2.141 & 2,88 & 24.867 & 1434 & 76 \\
\hline \multicolumn{2}{|l|}{ Dinamarca } & 3,05 & 2.210 & 2,97 & 26.082 & 812 & 54 \\
\hline \multicolumn{2}{|l|}{ Holanda } & 8,22 & 3.861 & 5,19 & 17.115 & 1949 & 45 \\
\hline \multicolumn{2}{|l|}{ Alemania } & 15,17 & 12.678 & 17,03 & 17.856 & 731 & 66 \\
\hline \multicolumn{2}{|l|}{ Francia } & 21,30 & 17.769 & 23,87 & 16.799 & 591 & 59 \\
\hline \multicolumn{2}{|l|}{ Reino Unido } & 8,67 & 8.122 & 10,91 & 20.226 & 493 & 70 \\
\hline \multicolumn{2}{|l|}{ Austria } & 2,31 & 1.719 & 2,31 & 11.561 & 498 & 47 \\
\hline \multicolumn{2}{|l|}{ Finlandia } & 1,51 & 937 & 1,26 & 5.022 & 431 & 33 \\
\hline \multicolumn{2}{|l|}{ Suecia } & 1,61 & 1.351 & 1,81 & 15.182 & 432 & 76 \\
\hline \multicolumn{2}{|l|}{ UE-15 } & 100,00 & 74.445 & 100,00 & 10.279 & 514 & 52 \\
\hline \multicolumn{8}{|c|}{$\begin{array}{ll}\text { FUENTE: } & \text { Datos calculados por GARCÍA ÁlvaREZ-COQUE (1998) para la ESP a partir de los co- } \\
& \text { eficientes de producción nacional suministrados por la base de datos SPEL. Los datos } \\
& \text { de empleo, superficie y VAB a c.f. tomados de COMISIÓN DE LA COMUNIDADES } \\
& \text { EUROPEAS (varios años). }\end{array}$} \\
\hline
\end{tabular}

CUADRO $\mathrm{N}^{\mathrm{O}}$ 7. Nivel de apoyo a la producción agrícola según la OCDE. *

\begin{tabular}{lrrrrrr}
\hline Zonas Geog. & $\mathbf{1 9 7 9 / 8 6}$ & $\mathbf{1 9 8 7}$ & $\mathbf{1 9 8 8}$ & $\mathbf{1 9 8 9}$ & $\mathbf{1 9 9 0}$ & $\mathbf{1 9 9 7}$ \\
\hline Australia & 12 & 11 & 9 & 10 & 11 & 9 \\
Canadá & 32 & 49 & 42 & 37 & 41 & 20 \\
CEE & 37 & 49 & 46 & 41 & 48 & 42 \\
Japón & 66 & 76 & 74 & 71 & 68 & 69 \\
USA & 28 & 41 & 34 & 29 & 30 & 16 \\
\hline
\end{tabular}

* Los datos miden el \% del valor de la producción agrícola protegida.

Fuente: Datos tomados de Escudero Zamora, G. (1991) y de Andrés, R. DE. y Urzaingui, E. (1995).

CUADRO $\mathrm{N}^{\circ}$ 8. Subvenciones de explotación según producciones en España. (millones de pts. corrientes).

\begin{tabular}{lrrrrrrrrr}
\hline Producciones & $\mathbf{1 9 9 0}$ & $\mathbf{1 9 9 1}$ & $\mathbf{1 9 9 2}$ & $\mathbf{1 9 9 3}$ & $\mathbf{1 9 9 4}$ & $\mathbf{1 9 9 5}$ & $\mathbf{1 9 9 6}$ & $\begin{array}{c}\mathbf{1 9 9 7} \\
\text { (P) }\end{array}$ & $\begin{array}{c}\mathbf{1 9 9 8} \\
(\mathbf{A})\end{array}$ \\
\hline P. Vegetal & 46.878 & 73.124 & 130.802 & 344.804 & 441.858 & 525.368 & 466.504 & 511.859 & 504.195 \\
P. Animal & 73.918 & 105.915 & 95.138 & 103.921 & 127.032 & 149.126 & 158.858 & 140.312 & 154.481 \\
Otras Subv. & 13.595 & 11.318 & 14.719 & 19.208 & 20.170 & 19.735 & 41.042 & 40.051 & 45.834 \\
\hline Total Subv, & 134.391 & 190.411 & 240.659 & 467.933 & 589.060 & 694.229 & 666.404 & 692.222 & 704.510 \\
\hline FuENTE: MAPA (Subdirección General de Estadística) (1.999). Elaboración propia. & &
\end{tabular}




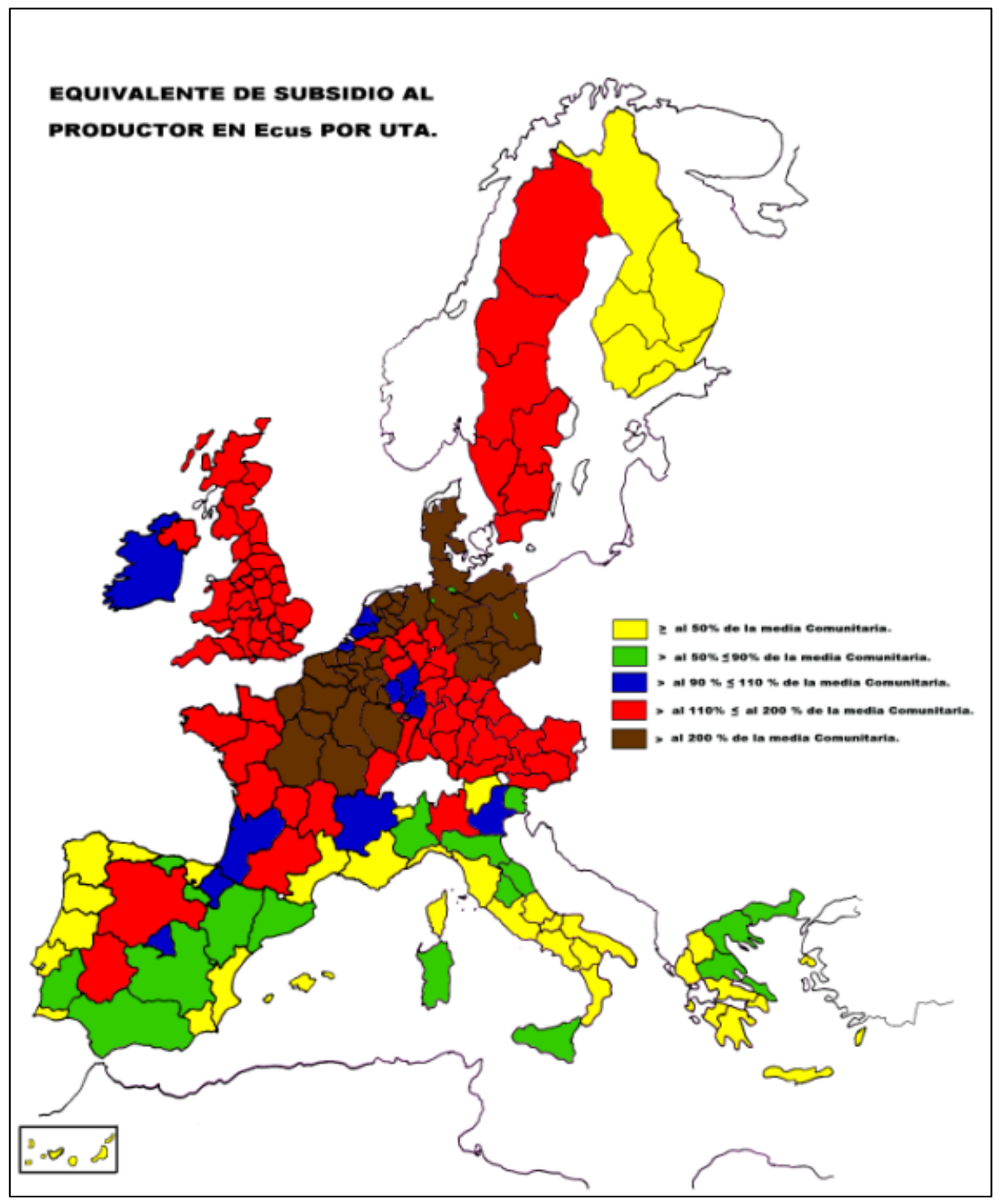


CUADRO N ${ }^{\circ}$ 9. Reparto de las subvenciones según Comunidades Autónomas. 1994.

\begin{tabular}{lrrrrrrrrr}
\hline \multicolumn{1}{c}{ CC.AA. } & \multicolumn{1}{c}{$(\mathbf{1})$} & $\mathbf{( 2 )}$ & \multicolumn{1}{c}{$(\mathbf{3})$} & \multicolumn{1}{c}{$\mathbf{( 4 )}$} & $\mathbf{( 5 )}$ & \multicolumn{1}{c}{$(\mathbf{6 )}$} & $\mathbf{( 7 )}$ & $\mathbf{( 8 )}$ & \multicolumn{1}{c}{$\mathbf{( 9 )}$} \\
\hline Andalucía & 724.817 & 234.805 & 207.900 & 540.671 & 32 & 777.351 & 30 & 43 & 1.129 .400 \\
Aragón & 131.690 & 68.162 & 49.500 & 85.078 & 52 & 228.601 & 30 & 80 & 1.377 .000 \\
Asturias & 37.861 & 4.244 & 42.600 & 38.836 & 11 & 63.882 & 7 & 11 & 99.600 \\
Baleares & 20.303 & 2.455 & 6.400 & 21.000 & 12 & 38.398 & 6 & 12 & 383.600 \\
\hline Canarias & 67.160 & 2.393 & 26.400 & 69.807 & 4 & 105.901 & 2 & 3 & 90.600 \\
Cantabria & 30.175 & 2.306 & 15.600 & 31.010 & 8 & 45.341 & 5 & 7 & 147.800 \\
Castilla- Mancha & 279.420 & 137.854 & 76.600 & 188.053 & 49 & 342.182 & 40 & 73 & 1.799 .700 \\
Castilla-León & 346.284 & 147.617 & 116.100 & 281.327 & 43 & 519.977 & 28 & 52 & 1.271 .500 \\
\hline Cataluña & 175.472 & 33.828 & 67.700 & 174.439 & 19 & 442.404 & 8 & 19 & 499.700 \\
C. Valenciana & 190.950 & 11.191 & 89.900 & 195.266 & 6 & 314.656 & 4 & 6 & 124.500 \\
Extremadura & 168.266 & 62.229 & 50.300 & 123.296 & 37 & 220.055 & 28 & 50 & 1.237 .200 \\
Galicia & 148.637 & 14.609 & 232.200 & 161.897 & 10 & 268.278 & 5 & 9 & 62.900 \\
\hline Madrid & 21.054 & 8.150 & 14.400 & 19.236 & 39 & 39.682 & 21 & 42 & 566.000 \\
Murcia & 115.963 & 12.614 & 40.900 & 110.962 & 11 & 196.276 & 6 & 11 & 308.400 \\
Navarra & 42.260 & 12.710 & 10.900 & 36.444 & 30 & 74.631 & 17 & 35 & 1.166 .100 \\
País Vasco & 44.392 & 7.642 & 14.700 & 41.157 & 17 & 67.769 & 11 & 19 & 519.900 \\
La Rioja & 37.926 & 5.088 & 9.900 & 36.006 & 13 & 53.735 & 9 & 14 & 513.900 \\
\hline Total & 2.582 .630 & 767.897 & 1.072 .000 & 2.154 .485 & 30 & 3.799 .119 & 20 & 36 & 716.300 \\
\hline
\end{tabular}

1: RA (millones pts); 2, Subvenciones (mill. pts); 3, Ocupados; 4, VABpm (mill. Pts); 5, 2/1 100; 6, PFA (mill. pts); 7, 2/6*100; 8, 2/4*100; 9, 2/3

FuENTE: MAPA. (Subdirección General de Estadística y Análisis Regional). (1.996). Elaboración propia.

RESUMEN: La PAC fue, es y sigue siendo la apuesta comunitaria más importante desde la creación de la CEE, tal y como lo demuestra su importancia presupuestaria. Es una política con logros evidentes y con fracasos llamativos como el desequilibrio social y regional que ha propiciado entre sus perceptores. Con variaciones en su trayectoria, se encamina, o debería hacerlo, hacia una política más rural, más integrada, más territorial en la que vaya perdiendo progresivamente relevancia su tradicional carácter productivista y sectorial. Dicha transformación se convierte en condición "sine qua non" para afrontar los retos que un mercado ampliado, la necesidad de una mayor integración exterior, la exigencias de calidad en las producciones o el respeto del medio ambiente le plantean.

PALABRAS CLAVES: PAC, política rural.

ABSTRACT: The CAP was and it continues being, the mast important communitary bet since the EEC was created, and so is showed by its budgetary importance. This is a politics that has had obvions succes and remarkable faitures like regional and social lack of balance that if has caused among its receivers. More or less, its line is directed, or so it must be, to a more rural, more integrated, and more territorial policy in which its traditionally sectoral and lucrative nature loses importance progressively. This change becomes the "sine qua non" condition to face the challenges that a more extended market, the necessity of a bigger outer integration, the productive quality demands, or the care of environment.

KEY WORDS: CAP, rural policy

RÉSUMÉ: La PAC a été le "pari” communnautaire le plus important depuis la création de laCEE, ou du moins, si l'on s'en tient à l'importance de son budget. C'est une politique pleine d'évidents succès, mais aussi remplie de nombreux échecs, comme le déséquilibre social et regional qu' elle a causé entre ses percepteurs. Avec des variations tout le long de sa trajectoire, elle se dirige, ou 
devrait le faire, vers une politique plus rurale, plus intégrée, et plus territoriale où son traditionnel caractère productiviste et sectorial devrait disparaître. Une telle transformation devient une condi tion "sine qua non" pour affronter les défis que un vaste marché, la nécéssité d'une plus grande intégration extérieur, les éxigences de qualité dans la production ou le respect à l'environnement, lui pasent.

MOTS-CLÉS: PAC, politique rurale. 